\title{
Vivir en tiempos de pestilencia
}

\author{
Jon Arrizabalaga \\ CSIC - Instituto Milà i Fontanals, Barcelona
}

Ruth MacKay, Life in a time of pestilence. The great Castilian Plague of I596-I60I

Cambridge University Press, Cambridge, 20I9, 275pp. ISBN 978-IIO8-49820-3

Life in a time of pestilence de Ruth MacKay ha aparecido publicada justamente a los cincuenta años de la obra, ya clásica, Recherches sur les grandes épidémies dans le nord de l'Espagne à la fin du Xviè siècle. Problèmes de documentation et de méthode (SEVPEN, París, I969), que Bartolomé Bennassar dedicó al tema, común entre ambas, de la llamada "peste atlántica» de I596-I602 en la península ibérica. La casualidad ha querido que la nueva monografía haya visto la luz en vísperas de la irrupción de la COVID-r9, una pandemia que ha despertado en el Norte global mucha mayor conciencia sobre la vulnerabilidad humana, y resucitado el interés por grandes epidemias históricas que hasta poco podían parecer propias de un casi prescindible pasado remoto.

La monografía objeto de la reseña constituye una muestra notable del impacto del llamado "giro espacial» en la historia social y cultural de las últimas décadas, en contraste con la orientación geográfica y cronológica prevalente en la obra de Bennassar, en la que la epidemia tenía un protagonismo estelar. A MacKay no le interesa tanto la peste como la experiencia vital a escala individual y colectiva que de ella se 
tuvo en un escenario político y cívico específico. De ahí que centre su análisis en las circunstancias y reacciones que su paso o amenaza propició en distintos «espacios» de este, y que las estructuras propias de la Monarquía Hispánica durante los años finales del reinado de Felipe II e iniciales del de Felipe III representen el trasfondo operante unas veces como freno y otras como acelerador de los acontecimientos desencadenados por la epidemia.

Sin dejar de rendir tributo a Bennassar, con quien comparte el propósito de contribuir a crear «una historia, basada en la documentación, de la peste en la Castilla en los años de transición entre el siglo Xvi y el XVII», MacKay se propone responder a cuestiones distintas a las suyas. A este objeto, explota un notable volumen de documentación municipal y real procedente de múltiples fondos archivísticos municipales, regionales y nacionales (sobre todo libros de actas y correspondencia afín, libros mayores contables y pleitos a consecuencia de la peste), a la vez que renuncia de modo expreso al uso de archivos parroquiales y al establecimiento de conclusiones demográficas, ambos aspectos bien presentes en la obra de Bennassar. La atención se focaliza en el territorio de la Corona de Castilla correspondiente al cuarto noroccidental de la península ibérica, particularmente localidades (pueblos, villas y ciudades) cántabras, castellano-leonesas, riojanas y vascas. La discusión se enriquece por el recurso a no pocos ejemplos procedentes de otras epidemias en ciudades europeas dentro y fuera de la península ibérica durante los siglos XVI, XVII e incluso XVIII, por más que MacKay deje claro que no se ha propuesto hacer un estudio comparativo.

En la obra de MacKay se exploran las circunstancias cotidianas de las comunidades humanas sujetas a la crisis epidémica, a través de diversos temas (memoria, costumbre, ley, caridad, deber, justicia, conocimiento y creencia). El análisis se estructura en siete grandes espacios conceptuales que sirven de epígrafes a sucesivos capítulos: el "palacio» como vocablo evocador de «la corte, la monarquía, la ley, el discurso y la ideología de la organización y lealtad políticas»; el "camino» por donde transeúntes de todo tipo, noticias y bienes seguían circulando, frente al mito historiográfico de los pueblos inmóviles; el «muro» como barrera más o menos permeable que en cada momento marcaba quién 
y qué entraban, y quién y qué no, en una determinada localidad; el «mercado» como lugar de abastecimiento e intercambio de alimentos, ganado y dinero; la "calle» como espacio «donde los sonidos, olores y visión de la peste transformaban los paisajes ordinarios», y escenario primordial de aplicación de las medidas de salud pública y de las dispares reacciones entre los diferentes actores sociales ante la presencia o amenaza de la peste; el «ayuntamiento" como centro rector de la vida colectiva, donde se dictaba la práctica totalidad de las medidas frente a la epidemia, y escenario de conflictos tanto en su seno como con otros ayuntamientos o con el poder real); y el «lecho del enfermo» como espacio en casas, hospitales o centros habilitados como tales, donde diversos prácticos suministraban alivio físico y espiritual a los apestados (pp. 7-8).

En las antípodas de la historiografía de las catástrofes, MacKay evita una visión "gótica» de la peste y de las respuestas sociales a una calamidad. En este sentido, no se priva de destacar, acertadamente, la perdurable contribución de Tucídides — con su descripción, en la Historia de la guerra del Peloponeso, del absoluto colapso social desencadenado por la llamada plaga o peste de Atenas - a la pervivencia de esta orientación histórica e historiográfica. Igualmente de modo acertado, evita conferir excesiva relevancia a la cuestión de la identidad de la peste histórica, por más que no ignore los actuales debates historiográficos en torno a ella (pp. II2-II4). A resultas de todo ello, su interés se focaliza «menos en lo excepcional que en lo habitual», por juzgar que, observando "cómo gente exhausta se cuidaba, o no, mutuamente en circunstancias excepcionales, podemos captar el poder de las reglas, leyes y costumbres que les unían» (p. II).

En su discusión a propósito de la organización asistencial frente a la peste, que ciertamente hubiera podido estructurarse mejor contando con más bibliografía reciente sobre la historia de los hospitales y de los procesos de consolidación hospitalaria en los reinos ibéricos entre los siglos XIV y XVII, se seńala que en junio de I599 el Consistorio municipal de Valladolid habilitó el Hospital de San Lázaro, antigua leprosería de la ciudad, junto al de San Bartolomé, ambos extramuros, para acoger pobres enfermos, al no disponer de ningún hospital intramuros 
equipado para atender apestados (pp. 233-234); un detalle que, a mi juicio, podría apuntar hacia una eventual reutilización, con el declive de la lepra y la profusión de epidemias en la Europa bajomedieval y temprano-moderna, de viejas leproserías en desuso para albergar pacientes aquejados de enfermedades pestilenciales.

Me gustaría, para acabar, hacer una precisión a propósito del único práctico sanitario sin formación reglada que MacKay ha podido localizar en la amplia documentación archivística consultada. Ciertamente, el vecino de Acevedo (León) Blas Díez, que aseguraba curar «la enfermedad de las bubos [sic.]», ofrece tal perfil (p. 216) pero me inclino a pensar que su presumida «especialidad» no era la "peste», sino el «mal de las bubas» o "gálico». No solo por la discordancia de género entre el artículo (las) y el sustantivo (bubos) que, además, no se recoge en el Tesoro de la lengua castellana de Sebastián de Covarrubias, sino también porque «las bubas» constituían entonces el mal incurable que quizá con mayor frecuencia este tipo de prácticos aseguraba curar con sus secretos remedios.

Nada de ello me impide subrayar el alto interés de esta monografía de Ruth MacKay cuyo relato nos ofrece un gran y bello tapiz acerca de la vida en tiempos de peste en la Castilla a caballo entre los siglos XVI y XVII. Su rico y matizado análisis revela hasta qué punto una sociedad de la Europa temprano-moderna como la castellana, lejos de verse abocada al colapso, fue capaz de hacer frente a las excepcionales circunstancias vividas y de desarrollar respuestas adaptativas que, en definitiva, le permitieron superar el reto colectivo de aquella grave crisis epidémica. Todo ello valida de forma bien convincente la tesis de partida de este excelente estudio. 